Review

\title{
Prospect for Application of PARP Inhibitor in Patients with HER2 Negative Breast Cancer
}

\author{
Nan Shao*, Yawei Shi*, Liang Yu, Runyi Ye, Zhen Shan, Zhanqiang Zhang, Yunjian Zhang, Ying Lin ${ }^{\bowtie}$ \\ Breast Disease Center, The First Affiliated Hospital, Sun Yat-Sen University, No. 58, ZhongShan Er Lu, Guangzhou, Guangdong, 510080, P.R. China \\ *Co-first authors \\ $\square$ Corresponding author: Ying Lin, MD, PhD; Breast Disease Center, The First Affiliated Hospital, Sun Yat-Sen University, No. 58, ZhongShan Er Lu, \\ Guangzhou, Guangdong, 510080, P.R.China. Email: linying3@mail.sysu.edu.cn; Phone: 8620-87755766-8198 \\ (C) Ivyspring International Publisher. This is an open access article distributed under the terms of the Creative Commons Attribution (CC BY-NC) license \\ (https://creativecommons.org/licenses/by-nc/4.0/). See http://ivyspring.com/terms for full terms and conditions.
}

Received: 2018.10.16; Accepted: 2018.12.13; Published: 2019.03.10

\begin{abstract}
Human epidermal growth factor receptor (HER2) negative metastatic breast cancer (BC) accounts for $73 \%$ of $B C$. The molecular analysis of this disease is essential for potential options for targeted therapy. Several promising clinical strategies are being evaluated which includes endocrine therapy, modified chemotherapy, angiogenesis inhibitors, immune checkpoint inhibitors, and anti-androgens. New therapeutic approaches are being developed that target $B C$ patients with germline mutations in either BRCAI, BRCA2 as well as BRCAness, a condition in which tumors have molecular similarity to BRCA-mutated tumors. Poly (ADP-ribose) polymerase inhibitors (PARPi) which are effective therapy in germline BRCA1 and BRCA2 mutations, are also observed to be effective in somatic mutations. Germline mutations in the homologous recombination pathway genes could also contribute to PARPi sensitivity. PARPi act as chemo- and radio-sensitizers by limiting the DNA-damage response and potentiating the activity of chemo- and radio-therapy when used alone or in combination with chemotherapy. Apart from PARPi as monotherapy, additional researches are ongoing in combination with cytotoxic chemotherapeutics and targeted agents in HER2 negative $B C$. This review aims at the most recent developments in the targeted therapy, summarizes the recent clinical trials outcomes, along with the overview of ongoing clinical trials in HER2 negative patients with BRCA1/2 mutations and sporadic tumors with BRCAness.
\end{abstract}

Key words: Her2 negative breast cancer, PARP inhibitors, BRCA, BRCAness, targeted therapy

\section{Introduction}

Breast cancer (BC) is a leading cause of cancer mortality in women accounting for approximately 500,000 deaths worldwide [1]. The estrogen receptor (ER), progesterone receptor (PR) and human epidermal growth factor receptor 2 (HER2) status play a vital role in determining prognosis and planning treatment strategies in $\mathrm{BC}$ patients [2,3].As per the National Cancer Institute's Surveillance, Epidemiology and End Results (SEER) 17 registries database that covers $28 \%$ of the US population, ER+/PR+/HER2BC accounted for $73 \%$, ER+/PR+/HER2+ for $10 \%$ ER-/PR-/HER+ for $5 \%$ and ER-/PR-/HER2- for $12 \%[4]$.

Poly(ADP-ribose) polymerase (PARP) is a family of enzymes cause PARylation (addition of poly-ADPribose) of target proteins involved in diverse cellular processes including DNA-repair, chromatin modification, transcription regulation, control of cell division, Wnt signaling and maintenance of telomeres [5-7]. PARP1 has a well-established role in the repair of damaged DNA by base excision repair(BER) process $[8,9]$. Cells with germline BRCA1/2(gBRCA1/2) mutation have deficient homologous recombination (HR) and rely on complementary DNA-repair process, where inhibition of PARP induces synthetic lethality and leads to cell death [10,11]. Poly(ADPribose) polymerase inhibitors (PARPi) not only selectively targets cells with gBRCA1/2 mutations 
used as monotherapy [12-14] but also shows potential benefit when used in combination with other therapeutic agents including chemotherapy, radio-therapy and targeted agents [15].

This review provides an overview of the homologous recombination defects (HRD) in HER2 negative $B C$, the role of PARP and PARPi in HER2 negative $B C$ and the use of PARPi in management of HER2 negative $B C$ as monotherapy or in combination with targeted agents in this subset of $\mathrm{BC}$ patients.

\section{HRD in BC with BRCA mutation (BRCAm) or BRCAness}

$B R C A 1$ and $B R C A 2$ are the tumor-suppressor genes involved in maintaining DNA integrity and genomic integrity through a DNA-repair process called HR [16,17]. Germline mutations in BRCA1 and BRCA2 are associated with a $50 \%-85 \%$ lifetime risk of $B C$ [18]. BRCAness is defined as the phenotype in which HRD exists in a tumor in the absence of a gBRCA1/2 mutation [19]. In addition, somatic mutations in BRCA1 and BRCA2, epigenetic silencing of BRCA1 by promoter methylation and gene deletion results in sporadic tumors which despite their normal gBRCA genes exhibit BRCAness, a phenotype with molecular and histopathological characteristics similar to BRCA-deficient disease [20].

\section{HRD and related gene mutation in $B C$}

BRCA1 and BRCA2 are the key components of HR pathway $[16,21,22]$. BRCA1 has a board role in the promotion and regulation of HR and colocalises with RAD51 at sites of DNA-damage. It also regulates HR in part through the modulatory role in the PALB2-dependent loading of BRCA2-RAD51 repair machinery at DNA strand breaks [23]. Germline mutations in other genes involved in HR-mediated DNA-repair predispose individuals to breast or ovarian cancers. These include pathogenic mutation of ATM/ATR, amplification of pathogenic mutation of $E M S Y$, promoter methylation of RAD51C, mutation of $P T E N$ and mutation of fanconi's anemia genes [22,24]. In addition to these germline mutations in HR-associated genes, somatic mutations in HR genes, epigenetic silencing, copy number alterations and structural rearrangements also results in $H R$ deficiency [25]. The PIK3CA and TP53 mutations are predominant in triple negative $\mathrm{BC}$ (TNBC) with mutation frequency of $10-20 \%$ and $60-80 \%$ respectively [26,27]. TP53 mutations are more common in the basal-like (62-80\%); while, PIK3CA mutations are more frequent in Luminal-type $(46.2 \%)$ than the other subtypes [28]. The genomic alterations and/or epigenetic silencing in other HR pathway genes including ATR, ATM, RAD51/54, CHK1/2, NBS1,
PTEN, BARD1, RAD51C, RAD51D, BRIP1, PALB2 and HORMAD1 protein over-expression also confer BRCAness and render cells sensitive to DNAdamaging agents $[29,30]$. In BRCA1/2 proficient tumors, the over-expression of ID4 or HORMAD 1 leads to genomic instability and BRCAness $[19,28]$. The mutations in HR and the tumors resulting from these mutations are shown in Table 1.

Table 1. Germline and somatic genes mutations involved in HR and related tumors [19]

\begin{tabular}{|c|c|c|}
\hline Gene & $\begin{array}{l}\text { Tumor types with somatic } \\
\text { alterations (mutation, deletion or } \\
\text { promoter hypermethylation) }\end{array}$ & $\begin{array}{l}\text { Tumor types or } \\
\text { syndromes with } \\
\text { germline mutation }\end{array}$ \\
\hline BRCA 1 & $\begin{array}{l}\text { TNBC, HGSOC, lung cancer, prostate } \\
\text { cancer, mCRPC, and PDAC. }\end{array}$ & $\begin{array}{l}\text { TNBC, HGSOC and } \\
\text { PDAC }\end{array}$ \\
\hline BRCA 2 & $\begin{array}{l}\text { BC, HGSOC, PDAC, prostate cancer, } \\
\text { mCRPC, gastric, bladder and lung } \\
\text { cancer, DLBCL and sarcoma }\end{array}$ & $\begin{array}{l}\text { BC, HGSOC, PDAC and } \\
\text { leukemia }\end{array}$ \\
\hline ATM & $\begin{array}{l}\text { T-PLL, BC, GBM, ccRCC, lung } \\
\text { adenocarcinoma, sarcoma, and } \\
\text { prostate, gastric, bladder, colorectal, } \\
\text { uterine and pancreatic cancer }\end{array}$ & $\begin{array}{l}\text { Leukemia, lymphoma, } \\
\text { medulloblastoma, glioma } \\
\text { and ataxia telangiectasia }\end{array}$ \\
\hline ATR & $\begin{array}{l}\text { Breast, colorectal, head and neck, } \\
\text { gastric and uterine cancer }\end{array}$ & $\begin{array}{l}\text { Oropharyngeal cancer } \\
\text { and familial cutaneous } \\
\text { telangiectasia and cancer } \\
\text { syndrome }\end{array}$ \\
\hline $\begin{array}{l}\text { CHEK } 2 \\
\text { (CHK2) }\end{array}$ & Uterine cancer and HGSOC & BC \\
\hline PALB2 & Gastric cancer and HGSOC & $\begin{array}{l}\text { Wilms tumor, } \\
\text { medulloblastoma, AML, } \\
\text { Fanconi anemia, BC, } \\
\text { PDAC and HGSOC }\end{array}$ \\
\hline \multicolumn{3}{|c|}{$\begin{array}{l}\text { AML, acute myeloid leukemia; ATM, ataxia telangiectasia mutated; ATR, ataxia } \\
\text { telangiectasia; DLBCL, diffuse large B cell lymphoma; GBM, glioblastoma; ccRCC, } \\
\text { clear cell renal cell carcinoma; HGSOC, high grade serous-ovarian cancer, mCRPC, } \\
\text { metastatic castration-resistant prostate cancer; PDAC, pancreatic ductal } \\
\text { adenocarcinoma, TNBC, triple negative breast cancer; T-PLL, T-cell } \\
\text { prolymphocytic leukemia; WRN, Werner syndrome, RecQ helicase-like. }\end{array}$} \\
\hline
\end{tabular}

\section{The role of PARP and PARP inhibitors DNA-repair-PARP 1-Synthetic lethality}

Single stranded breaks (SSBs) are repaired by nucleotide excision repair (NER), BER, mismatch repair and translational synthesis. However, double stranded breaks (DSBs) are repaired either by HR or non-homologous end joining (NHEJ). PARP, a nuclear protein has diverse role in DNA-repair, chromatin modification, transcription regulation, control of cell division, cell death and metabolism [31]. There are around 17 members in PARP family and PARP1 accounts for the majority of these and plays an important role in SSBs [32] PARP1 controls the repair of SSBs in DNA through BER pathway [33]. PARP2 works along with PARP1 in DNA base excision repair [34]. Both of these act as DNA-damage sensors and are involved in the process of repair [35].

PARPi specifically prevent PARylation by competing with nicortinamide adenine dinucleotide (NAD+) site of PARP enzymes [36,37]. This causes 
PARP-trapping and eventually leads to disrupted DNA-repair, replication, transcription and DSBs $[34,38,39]$. PARPi cause PARP-trapping where PARP enzyme does not disengage from the damaged DNA sites which not only leads to unrepaired SSBs but also to generation and persistence of secondary DSBs. The trapped PARP-DNA complexes also make chromatin inaccessible to other DNA repairing enzymes, further promoting sustained DNA-damage [40]. Widely used PARPi are olaparib, rucaparib, niraparib, veliparib and talazoparib. It is observed that PARP-trapping potency varies widely among the inhibitors with niraparib having highest potency followed by olaparib and veliparib [34]. Earlier trials were designed to study the role of PARPi in BC patients with BRCA1/2 mutations. It is observed that cells with mutated or deficient BRCA1 and BRCA2 are unable to utilize the HR pathway of DNA-repair and they rely on complementary pathways such as BER. PARPi effectively eliminate cells capacity to repair SSBs through BER forcing the cells to die from accumulated unrepaired DNA breaks, representing the concept of synthetic lethality [41]. Synthetic lethality is defined as the phenomenon in which the combination of two non-lethal defects leads to cell death [42,43]. This effectiveness of PARPi was observed in clinical trials that showed significant improvement in terms of efficacy in $\mathrm{BC} /$ ovarian cancer patients harboring BRCA1/2 mutations [44]. PARPi disrupts several processes that involve PARPs including identification of damage and repair of DNA, S-phase events including replication, HRR and NHEJ [34,35,45-47]. PARPi cause accumulation of DSBs at the site of DNA-damage by interfering with replication fork and causing genomic instability $[48,49]$. PARPi when used in combination with other drugs acts mainly by two mechanisms namely PARP-trapping or catalytic inhibition of PARP enzymes. PARPi when used with chemotherapy enhances the treatment response due to the synergic effect of the treatments as both work by exploiting the DNA-damage/repair mechanism. For example, temozolomide in combination with PARPi acts by enhancing PARP-trapping [50,51]. Similarly, combination of PARPi with gemcitabine synergically acts by preventing cell proliferation and enhancing apoptosis $[52,53]$. Ionizing radiation cause DNA-damage that necessitates the recruitment of PARP1 to the damaged site and by combining PARPi to ionizing radiation, radiosensitization is induced thus promoting tumor inhibition [54,55]. PARPi in combination with EGFRi can elicit apoptosis by causing HR deficient state as evoked by some EGFR mutations [56]. Similarly, IGF-1Ri cause PARPi sensitivity by creating BRCAness [57]. PI3Ki in combination with PARPi act by decreasing proliferation and enhancing tumor cell death by inhibiting 53BP1, a DNA-repair protein, localization to the DNA-damage site $[58,59]$. Checkpoint kinase inhibitors when used with PARPi seem to cause cell death by enhancing DNA-damage [60]. Understanding the mechanisms by which PARPi work has opened a plethora for research in using PARPi as monotherapy and combination therapy in managing $B C$ patients.

\section{PARPi in the management of BRCAm cancer}

\section{Monotherapy in BRCAm patients}

Approximately $70 \%$ of BRCA-mutated BCs are triple negative and seem to be sensitive to DNA-damaging agents such as cisplatin, carboplatin and PARPi [61,62]. PARPi are used either as monotherapy or combination with chemotherapy where they limit the DNA-damage response and potentiate the activity of chemo- and radio-therapy thus acting as chemo-and radio-sensitizers [63].

Olaparib is the first PARPi approved by the FDA for use in gBRCA mutated, HER2 negative metastatic BC who received prior chemotherapy [64]. This approval was based on the results of the phase-III OlympiaD trial, in which 302 patients with gBRCA mutation and HER2-negative $\mathrm{BC}$ were randomized to receive olaparib (300 $\mathrm{mg}$ twice daily) or physician choice chemotherapy (capacitabine, eribulin or vinorelbine in 21-day cycles). The study demonstrated that the median progress-free survival (PFS) was significantly longer in the olaparib group compared to chemotherapy group (HR: 0.58 (95\% CI: 0.43-0.80); $\mathrm{P}<0.001$; median 7.0 vs 4.2 months). Moreover, the response rate was higher in the olaparib group than the standard therapy group $(59.9 \%$ vs $28.8 \%)$ and relatively less proportion of patients experienced grade 3 or higher adverse events (AEs) $(36.6 \%$ vs $50.5 \%)$ [65].

In the phase-II, proof of concept trial women with BRCA $1 / 2$ mutations and advanced BC were assigned to two cohorts and treated with olaparib 400 $\mathrm{mg}$ bid (cohort 1) or $100 \mathrm{mg}$ bid (cohort 2) respectively. The study showed that patients with high-dose olaparib had better objective response rate (ORR) (41\% vs $22 \%$ ) and improved median PFS (5.7 months vs. 3.8 months) compared to low-dose. These results provide proof of concept of PARPi in patients with BC that have genetic loss of function of BRCA1/2-associated DNA-repair [66]. Kaufman et al, in a phase-II study evaluated the efficacy and safety of olaparib in a spectrum of BRCA1/2 associated cancers and reported an ORR of $31.1 \%, 13 \%, 21.7 \%$, and $50.0 \%$ in ovarian, breast, pancreatic and prostate cancers, respectively [67]. An ongoing OlympiA trial (NCT020 32823 ) is designed to evaluate the efficacy of olaparib 
as an adjuvant treatment in patients with BRCAmutated HER2 negative BC. The primary end point is invasive disease free survival and secondary endpoint is OS and safety [68].

Another PARPi niraparib has shown to significantly improve the PFS regardless of the presence or absence of gBRCA mutations or HRD status. In a randomized, double blind, placebocontrolled trial, phase-III trial (ENGOT-OV16/ NOVA) niraparib has shown the longer median PFS than placebo in the gBRCA ovarian cancer cohort (HR: 0.27; (95\%CI, 0.17 to 0.41); $\mathrm{P}<0.001$; median 21.0 vs 5.5 months) and non-gBRCA cohort (HR: $0.45,95 \%$ CI, 0.34 to 0.61 ; $<<0.001$; median 9.3 vs 3.9 months). Moreover, niraparib also increased PFS in the non-gBRCA cohort for patients with HRD tumor (HR: 0.38 ; $95 \% \mathrm{CI}, 0.24$ to 0.59 ; $\mathrm{P}<0.001$, median 12.9 vs. 3.8 months). Thrombocytopenia, anemia and neutropenia are the common grade 3 or 4 AEs reported in the niraparib group. These results elucidated that niraparib is not only effective in patients with gBRCA1/2, but also shows benefit in HRD positive tumors with wild-type BRCA as well as those with somatic mutations [69]. Based on these promising results in BRCA-like ovarian cancer, the ongoing $A B C$ study is designed to investigate the efficacy of niraparib in patients with advanced locally recurrent BRCA-like, HER2-negative BC (NCT02826512) [70], and also a phase I trial to evaluate the efficacy and safety of niraparib in neoadjuvant settings in HER2 negative and BRCA-mutated localized BC (NCT03329 937) [71]. A phase-III, randomized, open-label, multicenter study deigned to compared the efficacy of niraparib versus chemotherapy (eribulin, vinorelbine, capecitabine or gemcitabine) in previously treated HER2 negative BRCA mutation positive $B C$ patients is ongoing (NCT01905592). The primary objective is PFS and the secondary objective is OS [72,73]. These trials will provide data on the use of niraparib in HER-2 negative $\mathrm{BC}$ patients.

The potential usefulness of PARPi in the treatment setting beyond BRCA-mutant tumors is well reported in the ARIEL 2 study. ARIEL 2 is a phase-II, open-label, multicenter study in which 192 patients with recurrent, platinum-sensitive, highgrade ovarian carcinoma were classified into three HRD subgroups namely BRCA-mutant $(n=40)$, loss of heterozygosity $(\mathrm{LOH})$ high $(\mathrm{n}=82)$ or $\mathrm{LOH}$ low $(\mathrm{n}=70)$. Patients were treated with rucaparib $600 \mathrm{mg}$ bid until disease progression. The study reported that the median PFS was significantly longer in the BRCAmutant (HR, 0.27; 95\% CI, 0.16-0.44; $\mathrm{P}<0.0001)$ and $\mathrm{LOH}$ high subgroups (HR, 0.62; 95\% CI, 0.42-0.90; $\mathrm{P}=0.011)$ compared with $\mathrm{LOH}$ low subgroup. The findings showed that tumor-based assays combining
BRCA mutation status and percentage of genomicwide $\mathrm{LOH}$ could identify patients with platinumsensitive carcinomas without gBRCA mutation who are likely to respond to rucaparib treatment. Moreover, it also demonstrated that the mutation and methylation status of HR-related genes such as RAD51C is associated with high genomic $\mathrm{LOH}$ in BRCA wild-type tumors and with rucaparib response [74]. Other than ovarian cancer, rucaparib has also shown activity in a phase I study of patients with HRD BC [75]. Based on this phase-II results, a single arm, open-label, multicenter phase-II study is currently evaluating the efficacy of rucaparib in patients with HER-negative metastatic BC with BRCAness phenotype defined by high tumor genomic $\mathrm{LOH}$ or somatic BRCA1/2 mutation without known gBRCA1/2 mutation (RUBY, NCT02505048) [76].

A recent study on characterization of $B C$ patient-derived xenografts generated from residual tumor surgical samples representing the heterogenous genomic alterations of TNBC revealed variation in sensitivity towards chemotherapy with no tumor regression, however, dramatic regression was observed with PARPi talazoparib. It is noteworthy that PARPi alone or in combination with chemotherapeutic agents also demonstrated activity in wild-type BRCA1/2 tumors suggesting the role of combination therapy in enhancing anti-tumor efficacy [77]. A ongoing phase-II trial (NCT02401347) is designed to assess the efficacy of talazoparib in TNBC with HRD and HER2 negative BC with HRD. This trial will evaluate its outcomes in terms of the ORR, CBR, PFS and safety [78]. EMBRACA (NCT01945775), an open-label, phase-III trial compared efficacy and safety of talazoparib with chemotherapy (capecitabine, eribulin, gemcitabine, or vinorelbine) in advanced or metastatic HER-2 negative BC with BRCA1 or 2 mutation. Among the 431 patients randomized to talazoparib $(\mathrm{n}=287)$ and chemotherapy $(\mathrm{n}=144)$, significant prolonged PFS was observed in talazoparib group [8.6 months (7.2-9.3)] compared to chemotherapy [5.6 months (4.2-6.7], HR=0.542 $(<0.0001)$. The ORR was statistically significant, $62.6 \%$ vs $27.2 \%$, respectively $(\mathrm{OR}=4.99, P<.0001)$ with median duration of response being 5.4 vs 3.1 months in talazopanib and chemotherapy, respectively. Additionally the talazoparib was well tolerated with less non-hematological toxicity [79]. Based on the results of EMBRACA trial FDA and EMA has accepted review of regulatory submission of talazoparib for treatment of patients with gBRCA mutated, HER2-negative BC [80].

A meta-analysis comparing PARPi monotherapy with mono-chemotherapy revealed PARPi monotherapy significantly improved PFS and ORR, HR=0.56 
(95\% CI 0.45 to 0.70$)$ and $\mathrm{OR}=4.15$ (95\% CI 2.82 to 6.10), respectively, however there was no difference in OS. PARPi monotherapy was also well tolerated and useful in delaying time to QoL deterioration $\mathrm{HR}=0.40$ (95\% CI 0.29 to 0.54 ), suggesting PARPi monotherapy to be effective in patients with BRCAm HER2negative $B C$ [81].

\section{Combination strategies and trials of PARPi}

\section{Combining PARPi with cytotoxic chemotherapy and radio-therapy}

Though PARPi are approved as monotherapy for selected patient population, they are also tested in combination with other cytotoxic and targeted agents. Kummar tested the chemo-potentiating effect of veliparib and low-dose cyclophosphamide in patients with refractory solid tumors and found that the combination is well tolerated with promising activity in patients with BRCA mutations. Of the 35 patients enrolled in this study, 7 patients had partial response and 6 additional patients had disease stabilization for at least six cycles [82]. Based on the encouraging results, the activity of metronomic cyclophosphamide alone or in combination with veliparib is being tested in a multicenter, randomized, phase-II study in patients with peritoneal cancer, fallopian tube cancer, high grade serous-ovarian cancer (HGSOC) and $B R C A$-mutant ovarian cancer patients that have not responded to standard therapies (NCT01306032) [83]. A phase I trial of veliparib with cyclophosphamide has demonstrated anti-tumor activity in BRCA-mutated HER2 negative BC [84]. The addition of veliparib-carboplatin to the standard paclitaxel followed by doxorubicin-cyclophosphamide regimen has also shown higher rates of pathological complete response than the standard therapy alone $(51 \%$ vs $26 \%$ ) in TNBC patients. However, patients in the veliparib-carboplatin group reported a high incidence of toxicity than the control group [85]. Phase I/II trial was designed to assess the efficacy of veliparib monotherapy and post progression combination therapy of veliparib with carboplatin in BRCA1/2 mutated metastatic BC. The PFS and OS was 8.7 and 18.8 months, respectively. Moreover veliparib monotherapy or combination therapy was safe in this strategy [86]. Another phase-II trial has investigated whether the addition of veliparib to temozolomide or carboplatin/paclitaxel provides clinical benefit over carboplatin/paclitaxel with placebo in patients with gBRCA1/2 mutated locally recurrent or metastatic BC (NCT01506609) [87]. There was increase in PFS (14.1 and 12.3 months, $\mathrm{HR}=0.789$; 95\% CI 0.536-1.162; $\mathrm{P}=0.227)$ and $\mathrm{OS}(28.3$ and 25.9 months, $\mathrm{HR}=0.750$; 95\% CI 0.503-1.117; $\mathrm{P}=0.156$ ) in patients receiving veliparib with carboplatin/paclitaxel compared to placebo plus carboplatin/paclitaxel, though the increase was statistically insignificant. However, addition of veliparib improved ORR significantly, $77.8 \%$ and $61.3 \%(\mathrm{P}=0.027)$ [88].

Lee et al. studied the safety and clinical activity of olaparib in combination with carboplatin in a phase $1 / 1 \mathrm{~b}$ trial in patients with ovarian/BC harboring BRCA1/2 mutations $(N=45)$. The results showed that the combination therapy was safe although in the intermittent schedule the dose limiting toxicity was not reached. The adverse events of grade $3 / 4$ were neutropenia, thrombocytopenia and anemia in $42.2 \%$, $20.0 \%$ and $15.6 \%$ respectively. The preliminary clinical efficacy revealed response rates of $44.1 \%$ and $87.5 \%$ in ovarian and $\mathrm{BC}$ patients suggestive of the additive effect of the treatment regimens [89]. Another phase 1 study evaluating the safety and efficacy of paclitaxel in combination with olaparib in metastatic TNBC. It was observed that though the combination was efficacious in terms of response rates $(37 \%)$, the neutropenia rates were $58 \%$ which were much higher than expected. This study was terminated in phase I and could not proceed to phase-II as an optimum dose could not be identified that could be of use in phase-II [63]. REVIVAL, a phase-II ongoing study is designed to study the efficacy of carboplatin-olaparib followed by olaparib monotherapy versus capecitabine in BRCA1/2 mutated HER2-negative BC [90].

In addition to their role as chemo-sensitizers, PARPi also potentiate the anti-tumor activity of radiation therapy. The addition of veliparib (10-300 $\mathrm{mg}$, orally BID) to whole brain radiation therapy in patients with brain metastasis from primary solid tumors improved the median survival time for NSCLC and BC subgroups with no increase in toxicities [91]. A phase I TBCRC 024 trail assessed the concurrent veliparib with chest wall and nodal radio-therapy in $\mathrm{BC}$ patients, revealed the importance of continuous monitoring for radio-therapy related toxicity [92]. The list of ongoing studies where PARP inhibitors are tested in combination with chemo- and radiation therapy is presented in Table 2.

\section{PARPi in combination with targeted agents}

PARPi are also tested in combination with EGFR (epidermal growth factor receptor) inhibitors, insulin like growth factor 1 receptor (IGF-1R) inhibitors, vascular endothelial growth factor (VEGFR) inhibitors, histone deacetylases (HDAC) inhibitors, phosphatidylinositol-3-kinase-protein kinase B-mammalian target of rapamycin (PI3K-AKT-mTOR) inhibitors, heat shock protein (HSP90) inhibitors and check point kinase 1/2 (CHK1/2) inhibitors and immune checkpoint inhibitors (CTLA4 and PD-1/PD-L1/L2 antagonists) [93]. 
Table 2. Ongoing clinical trials evaluating PARPi in combination with chemo-and radio-therapy in HER2 negative BC

\begin{tabular}{|c|c|c|c|c|}
\hline $\begin{array}{l}\text { PARP } \\
\text { inhibitor }\end{array}$ & Phase & Study population/tumor type & Treatment & NCT \\
\hline Olaparib & II/III & TNBC and/or gBRCA BC & Olaparib + paclitaxel + carboplatin & NCT03150576 \\
\hline Olaparib & I & TNBC and advanced ovarian cancer & Olaparib + paclitaxel + carboplatin & NCT00516724 \\
\hline Olaparib & I & Advanced HER2 negative BRCA1/2 mutated BC & $\begin{array}{l}\text { Olaparib+carboplatin followed by Olaparib } \\
\text { monotherapy vs Capecitabine }\end{array}$ & NCT02418624 \\
\hline Olaparib & I & $\begin{array}{l}\text { Inflammatory, loco-regionally advanced or metastatic TNBC or patient } \\
\text { with operated TNBC with residual disease }\end{array}$ & Olaparib+ radiation therapy & NCT03109080 \\
\hline Olparib & I & Locally Advanced Malignant Neoplasm, Inflammatory BC, TNBC & Olaparib+ radiation therapy & NCT02227082 \\
\hline Veliparib & III & $\begin{array}{l}\text { Metastatic HER2 negative or locally advanced unresectable } \\
\text { BRCA-associated BC }\end{array}$ & Veliparib+ carboplatin+ paclitaxel & NCT02163694 \\
\hline Veliparib & I & $\mathrm{BC}$ & Veliparib+radiation therapy & NCT01618357 \\
\hline Rucaparib & II & $\begin{array}{l}\text { Patients with invasive TNBC or ER/PR+, HER2 negative with known } \\
\text { BRCA1/ } 2 \text { mutations }\end{array}$ & Rucaparib+ cisplatin & NCT01074970 \\
\hline
\end{tabular}

EGFR-activating mutations, including gene amplification, as well as point mutations within the kinase domain have been detected in several solid tumors including TNBC. Preclinical studies have shown that EGFR inhibition alters the DNA DSB repair capacity and the lapatinib (EGFR1/2 inhibitor) induces a transient DNA DSB repair deficit in TNBC cells and subsequently augments cytotoxicity to veliparib through activation of intrinsic apoptosis pathway. Further molecular dissection reveals a novel regulation of HR involving EGFR and BRCA1 interaction and alteration of subcellular localization, and suggests that a contextual synthetic lethality exist between EGFR inhibitor and PARPi [94].

Cells with mutated BRCA1 have impaired HR function and also show increased expression of IGF-1R [95]. Therefore, dual inhibition of IGF-1R and PARP might increase the clinical efficacy in HRD patients and increase the population of patients who would benefit from PARPi. Amin et al. showed that ovarian and BC cells with deficient $\mathrm{HR}$ are sensitive to IGF-1R inhibition. Moreover, in HR proficient cells, IGF-1R inhibition reduced the mRNA and protein levels of RAD51 and sensitized these cells to olaparib [96].

The inhibition of angiogenesis creates a hypoxic state which is associated with impaired HR, specifically by decreasing the BRCA1 expression. Several studies have demonstrated that the anti-angiogenesis inhibitors bevacizumab and cediranib induce a higher incidence of hypoxia, reduction in HR and subsequent sensitivity to PARPi [93]. The safety and tolerability of olaparib/bevacizumab combination was assessed in the phase I study in patients with advanced solid tumors and showed that the combination was generally well tolerated with no dose limiting toxicities (DLTs) [97]. Liu assessed the toxicities and recommended phase 2 dosing (RP2D) of the cediranib/olaparib combination in recurrent ovarian and metastatic TNBC patients and showed that the combination has promising activity in ovarian cancer patients [98]. These studies support that the combination acts synergistically and is a viable treatment option for ovarian and BC patients.

$\mathrm{PI} 3 \mathrm{~K}$, in addition to regulating cellular processes including growth, metabolism and survival has an additional role in stabilizing and preserving DSB repairs by interacting with HR complex. Therefore, abrogation of PI3K signaling is being proposed as an approach to debilitate HR and potentiate PARPi therapy. Juvekar demonstrated that the combination of PI3K inhibitor (NVP-BKM120) and olaparib effectively delayed tumor growth in the mouse model compared to olaparib alone suggesting that the combination of PI3K and PARPi as an effective treatment for BRCA1-related tumors. Moreover, in BRCA-proficient TNBC cells, PI3K inhibition results in HR impairment and sensitization to PARPi through ERK-dependent BRCA1/2 downregulation [99]. Mo also demonstrated that mTOR inhibitors everolimus significantly suppressed HR repair and synergized with PARPi through regulating the expression of SUV39H1 in BRCA-proficient TNBCs and xenograft models [100]. On the basis of this preclinical evidence phase I studies assessing the safety and efficacy of the combinations are currently underway (NCT01623349, NCT02208375) [101,102].

Preclinical studies demonstrated that HDAC inhibitors attenuated the levels of DNA-damage response (DDR) and HR proteins induce BRCAness and sensitize TNBC cells to PARPi or cisplatin. The HDAC inhibitor induces acetylation and inhibition of chaperone activity of HSP90 which disrupts its association with its client proteins (ATR, BRCA1, RAD52 and CHK1) leading to depletion of their expression. Moreover, HDAC inhibitor and veliparib cotreatment induced more DNA strand breaks and synergistically induced apoptosis in TNBC cells [103]. In the TNBC xenografts model the combination also significantly reduced the in vivo tumor growth and markedly improved survival of mice [104]. These findings support the rationale to examine the clinical utility of this combination in TNBC, irrespective of BRCA1 mutation status. 
Table 3. Ongoing clinical trials evaluating PARPi in combination with targeted agents in HER2 negative BC

\begin{tabular}{|c|c|c|c|c|}
\hline $\begin{array}{l}\text { PARP } \\
\text { inhibitor }\end{array}$ & Phase & Study population/ tumor type & Treatment & NCT \\
\hline Olaparib & $\mathrm{I} / \mathrm{II}$ & $\begin{array}{l}\text { Recurrent ovarian, fallopian tube, peritoneal or TNBC patients with } \\
\text { gBRCA mutation }\end{array}$ & Olaparib+ Cediranib Maleate & NCT01116648 \\
\hline Olaparib & II & $\begin{array}{l}\text { Metastatic or unresectable solid tumors (TNBC, NSCLC, SCLC and } \\
\text { pancreatic adenocarcinoma) }\end{array}$ & Olaparib+ Cediranib Maleate & NCT02498613 \\
\hline Fluzoparib & I & $\begin{array}{l}\text { Recurrent ovarian or TNBC patients and subjects with deleterious } \\
\text { BRCA mutation }\end{array}$ & Fluzoparib + Apatanib & NCT03075462 \\
\hline Olaparib & I & Recurrent TNBC or HGSOC & Olaparib + PI3K inhibitor (BKM 120 or BYL719) & NCT01623349 \\
\hline Olaparib & $\mathrm{I} / \mathrm{II}$ & $\begin{array}{l}\text { Recurrent endometrial, TNBC, and ovarian, primary peritoneal, or } \\
\text { fallopian tube cancer }\end{array}$ & $\begin{array}{l}\text { Olaparib + mTORC1/2 inhibitor (AZD2014) \& AKT } \\
\text { inhibitor (AZD5363) }\end{array}$ & NCT02208375 \\
\hline Olaparib & I & $\begin{array}{l}\text { Metastatic, unresectable or recurrent solid tumors (ovarian, fallopian } \\
\text { tube, or primary peritoneal and TNBC) }\end{array}$ & Olaparib + Onalespib (HSP90 inhibitor) & NCT02898207 \\
\hline
\end{tabular}

\section{PARPi in combination with immune checkpoint inhibitors}

The normal function of immune checkpoint proteins is to regulating immune homeostasis, prevent excessive immune responses, including autoimmunity. Tumor cells exploit this immune regulatory pathway and it is one of the resistance mechanisms by which tumor cells evade the destruction of immune system. The characteristics of TNBC, namely the high mutational frequency which increases the chance of immunogenic mutations generating neoantigens makes TNBC a specific target for immune checkpoint inhibitors [105].

Higuchi used the immunocompetent BRCA1deficient murine ovarian cancer model to study the activity of immune checkpoint inhibitors either alone or in combination with veliparib and demonstrated that CTLA-4 antibody synergized therapeutically with veliparib resulting in protective anti-tumor immunity with significant survival benefit [106].

Jiao investigated the cross-talk between PARPi and immune checkpoint inhibitors in the tumor microenvironment and found that the PARPi attenuated anti-tumor immunity through upregulating PD-L1 expression in BC cells and animal models, and blockade of PD-L1 using PD-L1 antibodies re-sensitized PARPi-treated cells to T-cell mediated cytotoxicity. These data provides evidence that the combination of PARPi and PD-L1 antagonists increased the therapeutic efficacy compared to either agent alone in BC [107].

Based on the promising results obtained in preclinical studies, several ongoing clinical trials are evaluating the combination of PARPi in combination with PD-L1 antibodies including NCT03167619, NCT02484404, NCT02734004, NCT02657889 and NCT02849496 [108-112]. The first study reporting the clinical use of the durvalumab plus olaparib or cediranib combination therapy showed that the combinations are tolerable and active with partial response and stable disease reported in two and eight patients respectively, yielding an $83 \%$ disease control rate. In addition, of the 12 patients who received durvalumab and cediranib, six patients had partial response and three others had stable disease with a $75 \%$ disease control rate. The recommended phase 2 dosing was durvalumab $1500 \mathrm{mg}$ every 4 weeks with olaparib $300 \mathrm{mg}$ bid, or cediranib $20 \mathrm{mg}$, 5 days on/ 2 days off [113]. The ongoing trials assessing the safety and efficacy of the PARPi in combination with PD-L1 antagonists are shown in Table 4. Summary of completed trials of monotherapy and combination therapy of PARPi are represented in Table 5.

\section{Mechanism of resistance to PARPi}

Despite the promising results of the PARPi in BC it is observed that some of the patients eventually acquire resistance to this treatment. There are various underlying mechanisms leading to resistance to PARPi. Barber et al. investigated the cause of resistance in patients receiving olaparib and treatment naive using tumor biopsies by parallel DNA sequencing and identified BRCA2 secondary mutations in olaparib treated biopsies. They conclude that due to the BRCA2 secondary mutations, the activity of the BRCA2 protein $\mathrm{s}$ fully restored which causes resistance to PARPi [114]. Various other mechanisms that lead to PARPi resistance include HRR restoration due to TP53 binding protein 1 (53BP1) regulation, replication fork stabilization, additionally other causes include altered cell cycle regulation, altered miRNA-622, miRNA-182 expression, altered PARP expression and drug efflux $[115,116]$. 53BP1 strikes a balance between NHEJ and HR in normal cells, However, in case of downregulation or mutation in 53BP1 results in PARPi resistance as it induces BRCA1independent DNA end-resection [117]. Stabilization of the replication fork due to loss of Pax2 transactivation domain interacting (PTIP), a protein involved in HR also leads to PARPi resistance [118]. Altered MET, PI3K/AKT pathways are involved in causing resistance to PARPi $[119,120]$. There are certain challenges in using PARPi as combination therapy such as the dose limiting toxicities and development of resistance as most of the combination drugs also 
share similar mechanism of action as that of PARPi so are limited by their similar resistance mechanisms, This necessitates further research on identifying the subset of BC patients who would obtain maximum benefit from PARPi combination therapy and also in planning treatment strategies to overcome PARPi resistance.

\section{Conclusion and future prospective}

PARPi are highly effective approach for the treatment of cancers caused by defects in DNA-repair pathway. While the use of PARPi is currently restricted to patients with $\mathrm{gBRCA1/2}$ mutations, there are other somatic and germline abnormalities in the HR pathway genes that may contribute to sensitivity to PARPi in many cancers including HER2 negative BC. An important challenge lies in identification of patients with HRD and related gene mutations in HER2 negative and the effective treatment strategies for their management. Additional investigations including combination with cytotoxic chemotherapeutics and/or other targeted agents (VEGFR, EGFR, PI3K/ $\mathrm{AKT} / \mathrm{mTOR}$, HDAC, HSP90 and immune checkpoint inhibitors) are ongoing. Several preclinical studies demonstrated that these targeted agents have the potential to sensitize the HR proficient tumors to PARPi. The use of companion diagnostics to identify patients, finding and validating biomarkers that predict HR deficiency and response to PARPi will broaden the therapeutic horizon of these drugs in the future and also helps providing precision medicine to patients with cancer.

\section{Abbreviations}

BC: Breast cancer; DDR: DNA-damage response; DSB: Double stranded breaks; ER: Estrogen receptor; HGSOC: High grade serous-ovarian cancer; HR: Homologous recombination; HRD: Homologous recombination defects; LOH: Loss of heterozygosity; NHEJ: Non-homologous end joining; ORR: Objective response rate; PFS: Progress-free survival; PR: Progesterone receptor.

Table 4. Ongoing clinical trials evaluating PARPi in combination with Immune checkpoint inhibitors in HER2 negative BC.

\begin{tabular}{|c|c|c|c|c|}
\hline Clinicaltrials.gov identifier & Phase & Treatment & Tumor type & Outcome measures \\
\hline NCT03167619 & II & $\begin{array}{l}\text { Olaparib + Durvalumab } \\
\text { (anti-PD-L1) }\end{array}$ & Metastatic TNBC & PFS \\
\hline NCT03544125 & I & Olaparib + Durvalumab & Metastatic TNBC & $\begin{array}{l}\text { Proportion of completion of clinical } \\
\text { laboratory improvement amendments } \\
\text { analytics, Safety, ORR, CBR, DOR }\end{array}$ \\
\hline NCT02484404 & $\mathrm{I} / \mathrm{II}$ & $\begin{array}{l}\text { Olaparib and/or Cediranib + } \\
\text { Durvalumab (anti-PD-L1) }\end{array}$ & $\begin{array}{l}\text { Advanced solid tumors and advanced or } \\
\text { recurrent ovarian, TNBC, lung, prostate } \\
\text { and colorectal cancers }\end{array}$ & $\begin{array}{l}\text { Phase I: RP2D, safety } \\
\text { Phase-II: ORR }\end{array}$ \\
\hline NCT02734004 & $\mathrm{I} / \mathrm{II}$ & $\begin{array}{l}\text { Olaparib + Durvalumab } \\
\text { (anti-PD-L1) }\end{array}$ & $\begin{array}{l}\text { Advanced or metastatic solid tumors } \\
\text { (ovarian, breast, SCLC, gastric cancer) }\end{array}$ & DCR, safety and tolerability \\
\hline NCT02657889 & $\mathrm{I} / \mathrm{II}$ & $\begin{array}{l}\text { Niraparib + Pembrolizumab } \\
\text { (anti-PD-1) }\end{array}$ & $\begin{array}{l}\text { Advanced or metastatic TNBC or } \\
\text { recurrent ovarian cancer }\end{array}$ & $\begin{array}{l}\text { Phase I: RP2D, DLTs } \\
\text { Phase-II: ORR }\end{array}$ \\
\hline NCT02849496 & II & $\begin{array}{l}\text { Veliparib + Atezolizumab } \\
\text { (anti-PD-L1) }\end{array}$ & TNBC (stage III/IV) & PFS \\
\hline
\end{tabular}

Table 5. Summary of completed trials with PARPi, mono and combination therapy

\begin{tabular}{|c|c|c|c|c|}
\hline $\begin{array}{l}\text { Clinicaltrials.gov } \\
\text { identifier }\end{array}$ & Phase & Treatment & Tumor type & Outcome measures \\
\hline NCT02000622 & III & $\begin{array}{l}\text { Olaparib vs chemotherapy (capacitabine, } \\
\text { eribulin or vinorelbine) }\end{array}$ & HER2- BC & $\begin{array}{l}\text { Median PFS: } \\
7.0 \text { vs } 4.2 \text { months } \\
\text { Response rate: } \\
59.9 \% \text { vs } 28.8 \%\end{array}$ \\
\hline NCT00494234 & II & Olaparib: 400mg bid vs $100 \mathrm{mg}$ bid & $\begin{array}{l}\text { Advanced BC with BRCA1 or BRCA2 } \\
\text { mutations }\end{array}$ & $\begin{array}{l}\text { ORR: } 41 \% \text { vs } 22 \% \\
\text { Median PFS: } 5.7 \text { months vs } 3.8 \text { months }\end{array}$ \\
\hline NCT01078662 & II & Olaparib & $\begin{array}{l}\text { Ovarian, breast, pancreatic and } \\
\text { prostate cancers }\end{array}$ & ORR: $31.1 \%, 13 \% 21.7 \%$ and $50.0 \%$ \\
\hline NCT01945775 & III & Talazoparib vs Chemotherapy & $\begin{array}{l}\text { Advanced or HER2- BC with BRCA1 or } \\
2 \text { mutations }\end{array}$ & $\begin{array}{l}\text { PFS: } 8.6 \text { months vs } 5.6 \text { months } \\
\text { ORR: } 62.6 \% \text { vs } 27.2 \% \\
\text { Median DoR: } 5.4 \text { Vs } 3.2 \text { months }\end{array}$ \\
\hline NCT01042379 & II & $\begin{array}{l}\text { Veliparib-carboplatin vs standard therapy } \\
\text { alone }\end{array}$ & TNBC & $\begin{array}{l}\text { Pathological complete response rate: } 51 \% \text { vs } \\
26 \%\end{array}$ \\
\hline NCT01149083 & $\mathrm{I} / \mathrm{II}$ & Veliparib vs veliparib with carboplatin & $\begin{array}{l}\text { Metastatic BC with BRCA1/2 } \\
\text { mutations }\end{array}$ & PFS: 8.7 vs 18.8 months \\
\hline NCT01506609 & II & $\begin{array}{l}\text { Veliparib to temozolomide or } \\
\text { carboplatin/paclitaxel Vs } \\
\text { carboplatin/paclitaxel with placebo }\end{array}$ & $\begin{array}{l}\text { Metastatic BC with BRCA1/2 } \\
\text { mutations }\end{array}$ & $\begin{array}{l}\text { PFS: } 14.1 \text { vs } 12.3 \text { months } \\
\text { OS: } 28.3 \text { Vs } 25.9 \text { months } \\
\text { ORR: } 77.8 \% \text { vs } 61.3 \%\end{array}$ \\
\hline NCT02484404 & $\mathrm{I} / \mathrm{II}$ & Durvalumab plus olaparib or cediranib & Women's cancer & Disease control rate: $83 \%$ vs $75 \%$ \\
\hline
\end{tabular}




\section{Acknowledgements}

The authors acknowledge Dr Anuradha Nalli $(\mathrm{PhD})$ and Dr Amit Bhat (PhD) from Indegene, Bangalore, India for providing medical writing support and technical assistance in the development of this manuscript funded by AstraZeneca.

\section{Funding}

Funded by Sun Yat-Sen University Clinical Research 5010 Program

\section{Authors' contributions}

NS and YL carried out design, conception of the study and drafting the manuscript. YS, LY and RY participated in development of manuscript and critical revision. ZS, ZZ and $\mathrm{YZ}$ conducted all data acquisition, analysis and interpretation. All authors read and approved the final manuscript.

\section{Competing Interests}

The authors have declared that no competing interest exists.

\section{References}

1. Torre LA, Siegel RL, Ward EM, Jemal A. Global Cancer Incidence and Mortality Rates and Trends--An Update. Cancer Epidemiol Biomark Prev Publ Am Assoc Cancer Res Cosponsored Am Soc Prev Oncol. 2016;25(1):16-27.

2. Dawson S-J, Rueda OM, Aparicio S, Caldas C. A new genome-driven integrated classification of breast cancer and its implications. EMBO J. 2013 Mar 6;32(5):617-28.

3. Press MF, Bernstein L, Thomas PA, Meisner LF, Zhou JY, Ma Y, et al. HER-2/neu gene amplification characterized by fluorescence in situ hybridization: poor prognosis in node-negative breast carcinomas. J Clin Oncol Off J Am Soc Clin Oncol. 1997 Aug;15(8):2894-904.

4. Anderson WF, Rosenberg PS, Katki HA. Tracking and Evaluating Molecular Tumor Markers With Cancer Registry Data: HER2 and Breast Cancer. JNCI J Natl Cancer Inst [Internet]. 2014 May [cited 2018 Jun 21];106(5). https://academic.oup.com/jnci/article-lookup/doi/10.1093/jnci/dju093

5. Herceg Z, Wang ZQ. Functions of poly(ADP-ribose) polymerase (PARP) in DNA repair, genomic integrity and cell death. Mutat Res. 2001 Jun 2;477(1-2):97-110.

6. Morales J, Li L, Fattah FJ, Dong Y, Bey EA, Patel M, et al. Review of poly (ADP-ribose) polymerase (PARP) mechanisms of action and rationale for targeting in cancer and other diseases. Crit Rev Eukaryot Gene Expr. 2014;24(1):15-28.

7. Vyas S, Chang P. New PARP targets for cancer therapy. Nat Rev Cancer. 2014 Jun 5;14(7):502-9.

8. D'Amours D, Desnoyers S, D'Silva I, Poirier GG. Poly(ADP-ribosyl)ation reactions in the regulation of nuclear functions. Biochem J. 1999 Sep 1;342 ( Pt 2):249-68.

9. Satoh MS, Lindahl T. Role of poly(ADP-ribose) formation in DNA repair. Nature. 1992 Mar 26;356(6367):356-8.

10. Kyle S, Thomas HD, Mitchell J, Curtin NJ. Exploiting the Achilles heel of cancer: the therapeutic potential of poly(ADP-ribose) polymerase inhibitors in BRCA2-defective cancer. Br J Radiol. 2008;81:S6-11.

11. Farmer H, McCabe N, Lord CJ, Tutt ANJ, Johnson DA, Richardson TB, et al. Targeting the DNA repair defect in BRCA mutant cells as a therapeutic strategy. Nature. 2005 Apr 14;434(7035):917-21.

12. Bryant HE, Schultz N, Thomas HD, Parker KM, Flower D, Lopez E, et al. Specific killing of BRCA2-deficient tumours with inhibitors of poly(ADP-ribose) polymerase. Nature. 2005 Apr 14;434(7035):913-7.

13. Drew Y, Mulligan EA, Vong W-T, Thomas HD, Kahn S, Kyle S, et al. Therapeutic potential of poly(ADP-ribose) polymerase inhibitor AG014699 in human cancers with mutated or methylated BRCA1 or BRCA2. J Natl Cancer Inst. 2011 Feb 16;103(4):334-46.

14. Gelmon KA, Tischkowitz M, Mackay H, Swenerton K, Robidoux A, Tonkin K, et al. Olaparib in patients with recurrent high-grade serous or poorly differentiated ovarian carcinoma or triple-negative breast cancer: a phase 2, multicentre, open-label, non-randomised study. Lancet Oncol. 2011 Sep;12(9):852-61.

15. Rodler ET, Kurland BF, Griffin M, Gralow JR, Porter P, Yeh RF, et al. Phase I Study of Veliparib (ABT-888) Combined with Cisplatin and Vinorelbine in
Advanced Triple-Negative Breast Cancer and/or BRCA Mutation-Associated Breast Cancer. Clin Cancer Res. 2016 Jun 15;22(12):2855-64.

16. Roy R, Chun J, Powell SN. BRCA1 and BRCA2: different roles in a common pathway of genome protection. Nat Rev Cancer. 2011 Dec 23;12(1):68-78.

17. Huen MSY, Sy SMH, Chen J. BRCA1 and its toolbox for the maintenance of genome integrity. Nat Rev Mol Cell Biol. 2010 Feb;11(2):138-48.

18. Petrucelli N, Daly MB, Pal T. BRCA1- and BRCA2-Associated Hereditary Breast and Ovarian Cancer. In: Pagon RA, Adam MP, Ardinger HH, Wallace $\mathrm{SE}$, Amemiya A, Bean LJ, et al, editors. GeneReviews(®) [Internet]. Seattle (WA): University of Washington, Seattle; 1993. Available from: http://www.ncbi.nlm.nih.gov/books/NBK1247/

19. Lord CJ, Ashworth A. BRCAness revisited. Nat Rev Cancer. 2016 Feb;16(2):110-20.

20. Turner N, Tutt A, Ashworth A. Hallmarks of "BRCAness" in sporadic cancers. Nat Rev Cancer. 2004;4(10):814-9.

21. Prakash R, Zhang Y, Feng W, Jasin M. Homologous Recombination and Human Health: The Roles of BRCA1, BRCA2, and Associated Proteins. Cold Spring Harb Perspect Biol. 2015 Apr;7(4):a016600.

22. Stoppa-Lyonnet D. The biological effects and clinical implications of BRCA mutations: where do we go from here? Eur J Hum Genet. 2016 Sep;24:S3-9.

23. Scully R, Chen J, Plug A, Xiao Y, Weaver D, Feunteun J, et al. Association of BRCA1 with Rad51 in mitotic and meiotic cells. Cell. 1997 Jan 24;88(2):265-75.

24. Cancer Genome Atlas Research Network. Integrated genomic analyses of ovarian carcinoma. Nature. 2011 Jun 29;474(7353):609-15.

25. den Brok WD, Schrader KA, Sun S, Tinker AV, Zhao EY, Aparicio S, et al. Homologous Recombination Deficiency in Breast Cancer: A Clinical Review. JCO Precis Oncol. 2017 Jun 19;(1):1-13.

26. Sharma P. Biology and Management of Patients With Triple-Negative Breast Cancer. The Oncologist. 2016 Sep;21(9):1050-62.

27. Denkert C, Liedtke C, Tutt A, von Minckwitz G. Molecular alterations in triple-negative breast cancer-the road to new treatment strategies. Lancet Lond Engl. 2017 Jun 17;389(10087):2430-42.

28. Bianchini G, Balko JM, Mayer IA, Sanders ME, Gianni L. Triple-negative breast cancer: challenges and opportunities of a heterogeneous disease. Nat Rev Clin Oncol. 2016 Nov;13(11):674-90.

29. Lord CJ, Ashworth A. BRCAness revisited. Nat Rev Cancer. 2016 Feb;16(2):110-20.

30. McCabe N, Turner NC, Lord CJ, Kluzek K, Bialkowska A, Swift S, et al. Deficiency in the repair of DNA damage by homologous recombination and sensitivity to poly(ADP-ribose) polymerase inhibition. Cancer Res. 2006 Aug 15;66(16):8109-15.

31. Brown JS, O'Carrigan B, Jackson SP, Yap TA. Targeting DNA Repair in Cancer: Beyond PARP Inhibitors. Cancer Discov. 2017;7(1):20-37.

32. McLornan DP, List A, Mufti GJ. Applying synthetic lethality for the selective targeting of cancer. N Engl J Med. 2014 Oct 30;371(18):1725-35.

33. Cerrato A, Morra F, Celetti A. Use of poly ADP-ribose polymerase [PARP] inhibitors in cancer cells bearing DDR defects: the rationale for their inclusion in the clinic. J Exp Clin Cancer Res CR. 2016 Nov 24;35(1):179.

34. Murai J, Huang SN, Das BB, Renaud A, Zhang Y, Doroshow JH, et al. Trapping of PARP1 and PARP2 by Clinical PARP Inhibitors. Cancer Res. 2012 Nov 1;72(21):5588-99.

35. Kim MY, Zhang T, Kraus WL. Poly(ADP-ribosyl)ation by PARP-1: "PAR-laying" NAD+ into a nuclear signal. Genes Dev. 2005 Sep 1;19(17):1951-67.

36. Kotz J. PARP target practice. Sci-Bus Exch. 2012 Mar;5(13):323-323.

37. Wahlberg E, Karlberg T, Kouznetsova E, Markova N, Macchiarulo A, Thorsell A-G, et al. Family-wide chemical profiling and structural analysis of PARP and tankyrase inhibitors. Nat Biotechnol. 2012 Feb 19;30(3):283-8.

38. Murai J, Huang S-YN, Renaud A, Zhang Y, Ji J, Takeda S, et al. Stereospecific PARP trapping by BMN 673 and comparison with olaparib and rucaparib. Mol Cancer Ther. 2014 Feb;13(2):433-43.

39. Zeman MK, Cimprich KA. Causes and consequences of replication stress. Nat Cell Biol. 2014 Jan;16(1):2-9.

40. O'Sullivan Coyne G, Chen AP, Meehan R, Doroshow JH. PARP Inhibitors in Reproductive System Cancers: Current Use and Developments. Drugs. 2017 Feb;77(2):113-30.

41. Kelley MR, Logsdon D, Fishel ML. Targeting DNA repair pathways for cancer treatment: what's new? Future Oncol. 2014 May;10(7):1215-37.

42. Nijman SMB. Synthetic lethality: General principles, utility and detection using genetic screens in human cells. FEBS Lett. 2011 Jan 3;585(1):1-6.

43. Ledermann J, Harter P, Gourley C, Friedlander M, Vergote I, Rustin G, et al. Olaparib maintenance therapy in patients with platinum-sensitive relapsed serous ovarian cancer: a preplanned retrospective analysis of outcomes by BRCA status in a randomised phase 2 trial. Lancet Oncol. 2014 Jul;15(8):852-61.

44. Lord CJ, Tutt ANJ, Ashworth A. Synthetic lethality and cancer therapy: lessons learned from the development of PARP inhibitors. Annu Rev Med. 2015;66:455-70.

45. Schreiber V, Dantzer F, Ame J-C, de Murcia G. Poly(ADP-ribose): novel functions for an old molecule. Nat Rev Mol Cell Biol. 2006 Jul;7(7):517-28.

46. De Vos M, Schreiber V, Dantzer F. The diverse roles and clinical relevance of PARPs in DNA damage repair: current state of the art. Biochem Pharmacol. 2012 Jul 15;84(2):137-46.

47. Swindall AF, Stanley JA, Yang ES. PARP-1: Friend or Foe of DNA Damage and Repair in Tumorigenesis? Cancers. 2013 Jul 26;5(3):943-58. 
48. Davar D, Beumer JH, Hamieh L, Tawbi H. Role of PARP inhibitors in cancer biology and therapy. Curr Med Chem. 2012;19(23):3907-21.

49. Telli ML, Ford JM. PARP inhibitors in breast cancer. Clin Adv Hematol Oncol HO. 2010 Sep;8(9):629-35.

50. Gill SJ, Travers J, Pshenichnaya I, Kogera FA, Barthorpe S, Mironenko T, et al. Combinations of PARP Inhibitors with Temozolomide Drive PARP1 Trapping and Apoptosis in Ewing's Sarcoma. Sobol RW, editor. PLOS ONE. 2015 Oct 27;10(10):e0140988.

51. Murai J, Zhang Y, Morris J, Ji J, Takeda S, Doroshow JH, et al. Rationale for Poly(ADP-ribose) Polymerase (PARP) Inhibitors in Combination Therapy with Camptothecins or Temozolomide Based on PARP Trapping versus Catalytic Inhibition. J Pharmacol Exp Ther. 2014 May 1;349(3):408-16.

52. Hastak K, Alli E, Ford JM. Synergistic chemosensitivity of triple-negative breast cancer cell lines to poly(ADP-Ribose) polymerase inhibition, gemcitabine, and cisplatin. Cancer Res. 2010 Oct 15;70(20):7970-80.

53. Jacob DA, Bahra M, Langrehr JM, Boas-Knoop S, Stefaniak R, Davis J, et al. Combination therapy of poly (ADP-ribose) polymerase inhibitor 3 -aminobenzamide and gemcitabine shows strong antitumor activity in pancreatic cancer cells. J Gastroenterol Hepatol. 2007 May;22(5):738-48.

54. Albert JM, Cao C, Kim KW, Willey CD, Geng L, Xiao D, et al. Inhibition of poly(ADP-ribose) polymerase enhances cell death and improves tumor growth delay in irradiated lung cancer models. Clin Cancer Res Off J Am Assoc Cancer Res. 2007 May 15;13(10):3033-42.

55. Gani C, Coackley C, Kumareswaran R, Schütze C, Krause M, Zafarana G, et al In vivo studies of the PARP inhibitor, AZD-2281, in combination with fractionated radiotherapy: An exploration of the therapeutic ratio. Radiother Oncol J Eur Soc Ther Radiol Oncol. 2015 Sep;116(3):486-94.

56. Pfäffle HN, Wang M, Gheorghiu L, Ferraiolo N, Greninger P, Borgmann K, et al. EGFR-activating mutations correlate with a Fanconi anemia-like cellular phenotype that includes PARP inhibitor sensitivity. Cancer Res. 2013 Oct 15;73(20):6254-63.

57. Amin O, Beauchamp M-C, Nader PA, Laskov I, Iqbal S, Philip C-A, et al. Suppression of Homologous Recombination by insulin-like growth factor-1 inhibition sensitizes cancer cells to PARP inhibitors. BMC Cancer. 2015 Oct 29:15:817.

58. Juvekar A, Burga LN, Hu H, Lunsford EP, Ibrahim YH, Balmañà J, et al. Combining a PI3K inhibitor with a PARP inhibitor provides an effective therapy for BRCA1-related breast cancer. Cancer Discov. 2012 Nov;2(11):1048-63.

59. Yi YW, Park J-S, Kwak S-J, Seong Y-S. Co-treatment with BEZ235 Enhances Sensitivity of BRCA1-negative Breast Cancer Cells to Olaparib. Anticancer Res. 2015 Jul;35(7):3829-38,

60. Booth L, Cruickshanks N, Ridder T, Dai Y, Grant S, Dent P. PARP and CHK inhibitors interact to cause DNA damage and cell death in mammary carcinoma cells. Cancer Biol Ther. 2013 May;14(5):458-65.

61. Carey LA, Rugo HS, Marcom PK, Mayer EL, Esteva FJ, Ma CX, et al. TBCRC 001: Randomized Phase II Study of Cetuximab in Combination With Carboplatin in Stage IV Triple-Negative Breast Cancer. J Clin Oncol. 2012 Jul 20;30(21):2615-23.

62. Mo Q. Platinum based chemotherapy in triple negative breast cancer: A meta analysis. Oncol Lett [Internet]. 2012 Dec 28 [cited 2017 Oct 11]; Available from: http://www.spandidos-publications.com/10.3892/ol.2012.1093

63. Dent RA, Lindeman GJ, Clemons M, Wildiers H, Chan A, McCarthy NJ, et al. Phase I trial of the oral PARP inhibitor olaparib in combination with paclitaxel for first- or second-line treatment of patients with metastatic triple-negative breast cancer. Breast Cancer Res [Internet]. 2013 Oct [cited 2017 Oct 11];15(5). Available from: http:// breast-cancer-research.biomedcentral.com/articles/ $10.1186 /$ bcr3484

64. FDA approves olaparib for germline BRCA-mutated metastatic breast cancer [Internet]. FDA; Available from: https://www.fda.gov/Drugs/ InformationOnDrugs/ApprovedDrugs/ucm592357.htm

65. Robson M, Im S-A, Senkus E, Xu B, Domchek SM, Masuda N, et al. Olaparib for Metastatic Breast Cancer in Patients with a Germline BRCA Mutation. N Engl J Med. 2017;377(6):523-33.

66. Tutt A, Robson M, Garber JE, Domchek SM, Audeh MW, Weitzel JN, et al. Oral poly(ADP-ribose) polymerase inhibitor olaparib in patients with BRCA1 or BRCA2 mutations and advanced breast cancer: a proof-of-concept trial. Lancet Lond Engl. 2010 Jul 24;376(9737):235-44.

67. Kaufman B, Shapira-Frommer R, Schmutzler RK, Audeh MW, Friedlander M, Balmaña J, et al. Olaparib monotherapy in patients with advanced cancer and a germline BRCA1/2 mutation. J Clin Oncol Off J Am Soc Clin Oncol. 2015 Jan 20;33(3):244-50.

68. Olaparib as Adjuvant Treatment in Patients With Germline BRCA Mutated High Risk HER2 Negative Primary Breast Cancer (OlympiA) [Internet]. Clinical trials.gov; Available from: https://clinicaltrials.gov/ ct2/show/NCT02032823

69. Mirza MR, Monk BJ, Herrstedt J, Oza AM, Mahner S, Redondo A, et al. Niraparib Maintenance Therapy in Platinum-Sensitive, Recurrent Ovarian Cancer. N Engl J Med. 2016;375(22):2154-64.

70. A Feasibility Study of Niraparib for Advanced, BRCA1-like, HER2-negative Breast Cancer Patients - Full Text View - ClinicalTrials.gov [Internet]. [cited 2017 Sep 4]. Available from: https://clinicaltrials.gov/ct2/ show/NCT02826512

71. Study Evaluating the Antitumor Activity and Safety of Niraparib as Neoadjuvant Treatment [Internet]. Clinical trials.gov; Available from: https: / clinicaltrials gov/ct2/ show /NCT03329937?term=niraparib\&cond $=\mathrm{H}$ ER-2+negative+breast+cancer\&rank $=3$

72. Konstantinos Tryfonidis, Jan Bogaerts, Robert E. Martell, George W. Sledge, Judith Balmaña, M. William Audeh, Angelique Deleersnijder, Felicia Favorito, Shefali Agarwal, Giovanna Rizzetto, Carlo G. M. Messina, Leen Slaets, Theodora Goulioti, Andrew Tutt, David A. Cameron, Nicholas C. Turner. A phase III randomized trial of niraparib versus physician's choice in previously treated, HER2-negative, germline-BRCA mutated breast cancer patients: Intergroup study EORTC-1307-BCG and BIG5-13. Journal of Clinical Oncology [Internet]. Available from: http://ascopubs.org/doi/abs/ $10.1200 /$ jco.2014.32.15_suppl.tps659

73. A Phase III Trial of Niraparib Versus Physician's Choice in HER2 Negative, Germline BRCA Mutation-positive Breast Cancer Patients (BRAVO) [Internet]. Clinical trials.gov; Available from: https://clinicaltrials.gov/ct2/ show/study/NCT01905592

74. Swisher EM, Lin KK, Oza AM, Scott CL, Giordano H, Sun J, et al. Rucaparib in relapsed, platinum-sensitive high-grade ovarian carcinoma (ARIEL2 Part 1): an international, multicentre, open-label, phase 2 trial. Lancet Oncol. 2017 Jan;18(1):75-87.

75. Patsouris A, Vicier C, Campion L, Gouraud W, Jimenez M, Pezzella V, et al. An open-label, phase II study of rucaparib, a PARP inhibitor, in HER2metastatic breast cancer patients with high genomic loss of heterozygosity: RUBY. J Clin Oncol. 2017 May 20;35(15_suppl):TPS1117-TPS1117.

76. A Study to Assess the Efficacy of Rucaparib in Metastatic Breast Cancer Patients With a BRCAness Genomic Signature - Full Text View ClinicalTrials.gov [Internet]. [cited 2017 Sep 4]. Available from: https://clinicaltrials.gov/ct2/show/NCT02505048

77. Evans KW, Yuca E, Akcakanat A, Scott SM, Arango NP, Zheng X, et al. A Population of Heterogeneous Breast Cancer Patient-Derived Xenografts Demonstrate Broad Activity of PARP Inhibitor in BRCA1/2 Wild-Type Tumors. Clin Cancer Res Off J Am Assoc Cancer Res. 2017 Nov 1;23(21):6468-77.

78. Afghahi A, Chang P-J, Ford J, Telli M. Abstract OT2-05-04: The Talazoparib Beyond BRCA (TBB) trial: A phase II clinical trial of talazoparib (BMN 673) in BRCA1 and BRCA2 wild-type patients with (i) advanced triple-negative breast cancer (TNBC) and homologous recombination deficiency (HRD) as assessed by myriad genetics HRD assay, and (ii) advanced HER2-negative breast cancer (BC) with either a germline or somatic mutation in homologous recombination (HR) pathway genes. Cancer Res. 2016 Feb 15;76(4 Supplement):OT2-05-04-OT2-05-04.

79. Litton J, Rugo H, Ettl J, Hurvitz S, Gonçalves A, Lee K-H, et al. Abstract GS6-07: EMBRACA: A phase 3 trial comparing talazoparib, an oral PARP inhibitor, to physician's choice of therapy in patients with advanced breast cancer and a germline BRCA mutation. Cancer Res. 2018 Feb 15;78(4 Supplement):GS6-07-GS6-07.

80. FDA and EMA Accept Regulatory Submissions for Review of Talazoparib for Patients With Germline BRCA-Mutated Metastatic Breast Cancer [Internet]. ASCO; 2018 Jun. Available from: http://www.ascopost.com/News/58957?utm_source=TrendMD\&utm_medi $\mathrm{um}=\mathrm{cpc} \& u t \mathrm{t} \_$campaign=The_ASCO_Post_TrendMD_0

81. Poggio F, Bruzzone M, Ceppi M, Conte B, Martel S, Maurer C, et al. Single-agent PARP inhibitors for the treatment of patients with BRCA-mutated HER2-negative metastatic breast cancer: a systematic review and meta-analysis. ESMO Open. 2018;3(4):e000361.

82. Kummar S, Ji J, Morgan R, Lenz H-J, Puhalla SL, Belani CP, et al. A phase I study of veliparib in combination with metronomic cyclophosphamide in adults with refractory solid tumors and lymphomas. Clin Cancer Res Off J Am Assoc Cancer Res. 2012 Mar 15;18(6):1726-34.

83. Kummar S, Oza AM, Fleming GF, Sullivan DM, Gandara DR, Naughton MJ, et al. Randomized Trial of Oral Cyclophosphamide and Veliparib in High-Grade Serous Ovarian, Primary Peritoneal, or Fallopian Tube Cancers, or BRCA-Mutant Ovarian Cancer. Clin Cancer Res. 2015 Apr 1;21(7):1574-82.

84. Anampa J, Chen A, Wright J, Patel M, Pellegrino C, Fehn K, et al. Phase I Trial of Veliparib, a Poly ADP Ribose Polymerase Inhibitor, Plus Metronomic Cyclophosphamide in Metastatic HER2-negative Breast Cancer. Clin Breast Cancer. 2018 Feb;18(1):e135-42.

85. Rugo HS, Olopade OI, DeMichele A, Yau C, van 't Veer LJ, Buxton MB, et al. Adaptive Randomization of Veliparib-Carboplatin Treatment in Breast Cancer. N Engl J Med. 2016 Jul 7;375(1):23-34.

86. Somlo G, Frankel PH, Arun BK, Ma CX, Garcia AA, Cigler T, et al. Efficacy of the PARP Inhibitor Veliparib with Carboplatin or as a Single Agent in Patients with Germline BRCA1 - or BRCA2 -Associated Metastatic Breast Cancer: California Cancer Consortium Trial NCT01149083. Clin Cancer Res. 2017 Aug 1;23(15):4066-76

87. Isakoff SI, Puhalla S, Domchek SM, Friedlander M, Kaufman B, Robson M, et al. A randomized Phase II study of veliparib with temozolomide or carboplatin/paclitaxel versus placebo with carboplatin/paclitaxel in BRCA1 / 2 metastatic breast cancer: design and rationale. Future Oncol. 2017 Feb;13(4):307-20.

88. Han HS, Diéras V, Robson M, Palácová M, Marcom PK, Jager A, et al. Veliparib with temozolomide or carboplatin/paclitaxel versus placebo with carboplatin/paclitaxel in patients with BRCA1/2 locally recurrent/metastatic breast cancer: randomized phase II study. Ann Oncol Off J Eur Soc Med Oncol. 2018 Jan 1;29(1):154-61 
89. Lee J-M, Hays JL, Annunziata CM, Noonan AM, Minasian L, Zujewski JA, et al. Phase I/Ib Study of Olaparib and Carboplatin in BRCA1 or BRCA2 Mutation-Associated Breast or Ovarian Cancer With Biomarker Analyses. JNCI J Natl Cancer Inst [Internet]. 2014 Jun [cited 2018 Nov 7];106(6). Available from:

https://academic.oup.com/jnci/article-lookup/doi/10.1093/jnci/dju089

90. Schouten PC, Dackus GMHE, Marchetti S, van Tinteren H, Sonke GS, Schellens JHM, et al. A phase I followed by a randomized phase II trial of two cycles carboplatin-olaparib followed by olaparib monotherapy versus capecitabine in BRCA1- or BRCA2-mutated HER2-negative advanced breast cancer as first line treatment (REVIVAL): study protocol for a randomized controlled trial. Trials [Internet]. 2016 Dec [cited 2018 Jun 28];17(1). Available from:

http://trialsjournal.biomedcentral.com/articles/10.1186/s13063-016-1423-0

91. Mehta MP, Wang D, Wang F, Kleinberg L, Brade A, Robins HI, et al. Veliparib in combination with whole brain radiation therapy in patients with brain metastases: results of a phase 1 study. J Neurooncol. 2015 Apr;122(2):409-17.

92. Jagsi R, Griffith KA, Bellon JR, Woodward WA, Horton JK, Ho A, et al. Concurrent Veliparib With Chest Wall and Nodal Radiotherapy in Patients With Inflammatory or Locoregionally Recurrent Breast Cancer: The TBCRC 024 Phase I Multicenter Study. J Clin Oncol Off J Am Soc Clin Oncol. 2018 May 1;36(13):1317-22

93. Dréan A, Lord CJ, Ashworth A. PARP inhibitor combination therapy. Crit Rev Oncol Hematol. 2016 Dec;108:73-85.

94. Nowsheen S, Cooper T, Stanley JA, Yang ES. Synthetic lethal interactions between EGFR and PARP inhibition in human triple negative breast cancer cells. PloS One. 2012;7(10):e46614.

95. Hudelist G, Wagner T, Rosner M, Fink-Retter A, Gschwantler-Kaulich D, Czerwenka $\mathrm{K}$, et al. Intratumoral IGF-I protein expression is selectively upregulated in breast cancer patients with BRCA1/2 mutations. Endocr Relat Cancer. 2007 Dec;14(4):1053-62.

96. Amin O, Beauchamp M-C, Nader PA, Laskov I, Iqbal S, Philip C-A, et al. Suppression of Homologous Recombination by insulin-like growth factor-1 inhibition sensitizes cancer cells to PARP inhibitors. BMC Cancer. 2015 Oct 29;15:817.

97. Dean E, Middleton MR, Pwint T, Swaisland H, Carmichael J, Goodege-Kunwar P, et al. Phase I study to assess the safety and tolerability of olaparib in combination with bevacizumab in patients with advanced solid tumours. Br J Cancer. 2012 Jan 31;106(3):468-74.

98. Liu JF, Tolaney SM, Birrer M, Fleming GF, Buss MK, Dahlberg SE, et al. A Phase 1 trial of the poly(ADP-ribose) polymerase inhibitor olaparib (AZD2281) in combination with the anti-angiogenic cediranib (AZD2171) in recurrent epithelial ovarian or triple-negative breast cancer. Eur J Cancer Oxf Engl 1990. 2013 Sep;49(14):2972-8.

99. Ibrahim YH, García-García C, Serra V, He L, Torres-Lockhart K, Prat A, et al. PI3K inhibition impairs BRCA1/2 expression and sensitizes BRCA-proficient triple-negative breast cancer to PARP inhibition. Cancer Discov. 2012 Nov;2(11):1036-47.

100. Mo W, Liu Q, Lin CC-J, Dai H, Peng Y, Liang Y, et al. mTOR Inhibitors Suppress Homologous Recombination Repair and Synergize with PARP Inhibitors via Regulating SUV39H1 in BRCA-Proficient Triple-Negative Breast Cancer. Clin Cancer Res Off J Am Assoc Cancer Res. 2016 Apr 1;22(7):1699-712

101. Phase I Study of the Oral PI3kinase Inhibitor BKM120 or BYL719 and the Oral PARP Inhibitor Olaparib in Patients With Recurrent Triple Negative Breast Cancer or High Grade Serous Ovarian Cancer - Full Text View ClinicalTrials.gov [Internet]. [cited 2017 Sep 11]. Available from: https://clinicaltrials.gov/ct2/show/NCT01623349

102. A Phase Ib Study of the Oral PARP Inhibitor Olaparib With the Oral mTORC1/2 Inhibitor AZD2014 or the Oral AKT Inhibitor AZD5363 for Recurrent Endometrial, Triple Negative Breast, and Ovarian, Primary Peritoneal, or Fallopian Tube Cancer - Full Text View - ClinicalTrials.gov [Internet]. [cited 2017 Sep 11]. Available from: https://clinicaltrials.gov/ct2/show/NCT02208375

103. Ha K, Fiskus W, Choi DS, Bhaskara S, Cerchietti L, Devaraj SGT, et al. Histone deacetylase inhibitor treatment induces "BRCAness" and synergistic lethality with PARP inhibitor and cisplatin against human triple negative breast cancer cells. Oncotarget. 2014 Jul 30;5(14):5637-50.

104. Ha K, Fiskus W, Choi DS, Bhaskara S, Cerchietti L, Devaraj SGT, et al. Histone deacetylase inhibitor treatment induces "BRCAness" and synergistic lethality with PARP inhibitor and cisplatin against human triple negative breast cancer cells. Oncotarget. 2014 Jul 30;5(14):5637-50.

105. Migali C, Milano M, Trapani D, Criscitiello C, Esposito A, Locatelli M, et al. Strategies to modulate the immune system in breast cancer: checkpoint inhibitors and beyond. Ther Adv Med Oncol. 2016 Sep;8(5):360-74.

106. Higuchi T, Flies DB, Marjon NA, Mantia-Smaldone G, Ronner L, Gimotty PA, et al. CTLA-4 Blockade Synergizes Therapeutically with PARP Inhibition in BRCA1-Deficient Ovarian Cancer. Cancer Immunol Res. 2015 Nov;3(11):1257-68

107. Jiao S, Xia W, Yamaguchi H, Wei Y, Chen M-K, Hsu J-M, et al. PARP Inhibitor Upregulates PD-L1 Expression and Enhances Cancer-Associated Immunosuppression. Clin Cancer Res Off J Am Assoc Cancer Res. 2017 Jul 15;23(14):3711-20.

108. Phase II Multicenter Study of Durvalumab and Olaparib in Platinum tReated Advanced Triple Negative Breast Cancer (DORA) - Full Text View -
ClinicalTrials.gov [Internet]. [cited 2017 Sep 11]. Available from: https://clinicaltrials.gov/ct2/show/NCT03167619

109. Phase I/II Study of the Anti-Programmed Death Ligand-1 Antibody MEDI4736 in Combination With Olaparib and/or Cediranib for Advanced Solid Tumors and Advanced or Recurrent Ovarian, Triple Negative Breast, Lung, Prostate and Colorectal Cancers - Full Text View - ClinicalTrials.gov [Internet]. [cited 2017 Sep 11]. Available from: https://clinicaltrials.gov/ct2/show/NCT02484404

110. A Phase I/II Study of MEDI4736 in Combination With Olaparib in Patients With Advanced Solid Tumors. (MEDIOLA) [Internet]. Available from: https://clinicaltrials.gov/ct2/show/NCT02734004

111. Niraparib in Combination With Pembrolizumab in Patients With Triple-negative Breast Cancer or Ovarian Cancer (TOPACIO) [Internet]. Available from: https://clinicaltrials.gov/ct2/show/NCT02657889

112. Veliparib and Atezolizumab Either Alone or in Combination in Treating Patients With Stage III-IV Triple Negative Breast Cancer [Internet]. Available from: https://clinicaltrials.gov/ct2/show/NCT02849496

113. Lee J-M, Cimino-Mathews A, Peer CJ, Zimmer A, Lipkowitz S, Annunziata $\mathrm{CM}$, et al. Safety and Clinical Activity of the Programmed Death-Ligand 1 Inhibitor Durvalumab in Combination With Poly (ADP-Ribose) Polymerase Inhibitor Olaparib or Vascular Endothelial Growth Factor Receptor 1-3 Inhibitor Cediranib in Women's Cancers: A Dose-Escalation, Phase I Study. J Clin Oncol Off J Am Soc Clin Oncol. 2017 Jul 1;35(19):2193-202.

114. Barber LJ, Sandhu S, Chen L, Campbell J, Kozarewa I, Fenwick K, et al. Secondary mutations in BRCA2 associated with clinical resistance to a PARP inhibitor: Clinical PARP inhibitor resistance. J Pathol. 2013 Feb;229(3):422-9.

115. Kim Y, Kim A, Sharip A, Sharip A, Jiang J, Yang Q, et al. Reverse the Resistance to PARP Inhibitors. Int J Biol Sci. 2017;13(2):198-208.

116. Bitler BG, Watson ZL, Wheeler LJ, Behbakht K. PARP inhibitors: Clinical utility and possibilities of overcoming resistance. Gynecol Oncol. 2017 Dec;147(3):695-704.

117. Makvandi M, Xu K, Lieberman BP, Anderson R-C, Effron SS, Winters HD, et al. A Radiotracer Strategy to Quantify PARP-1 Expression In Vivo Provides a Biomarker That Can Enable Patient Selection for PARP Inhibitor Therapy. Cancer Res. 2016;76(15):4516-24.

118. Ray Chaudhuri A, Callen E, Ding X, Gogola E, Duarte AA, Lee J-E, et al. Replication fork stability confers chemoresistance in BRCA-deficient cells. Nature. 2016;535(7612):382-7.

119. Tapodi A, Debreceni B, Hanto K, Bognar Z, Wittmann I, Gallyas F, et al. Pivotal role of Akt activation in mitochondrial protection and cell survival by poly(ADP-ribose)polymerase-1 inhibition in oxidative stress. J Biol Chem. 2005 Oct 21;280(42):35767-75.

120. Veres B, Gallyas F, Varbiro G, Berente Z, Osz E, Szekeres G, et al. Decrease of the inflammatory response and induction of the Akt/protein kinase $B$ pathway by poly-(ADP-ribose) polymerase 1 inhibitor in endotoxin-induced septic shock. Biochem Pharmacol. 2003 Apr 15;65(8):1373-82. 